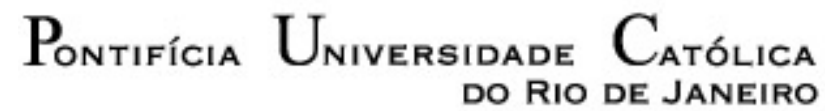

DO RIO DE JANEIRO

Roberto Betim Paes Leme

\title{
CONSUMO E TRANSFORMAÇÃO DA IMAGEM DO SURFE
}

Dissertação de Mestrado

Dissertação apresentada ao Programa de Pósgraduação em Design do Departamento de Artes \& Design da PUC-Rio como parte dos requisitos para obtenção do grau de Mestre em Design.

Orientador: Profa. Dra. Vera Damazio Co-orientador: Profa. Dra. Carla Dias 
Roberto Betim Paes Leme

\section{CONSUMO E TRANSFORMAÇÃO DA IMAGEM DO SURFE}

Dissertação apresentada como requisito parcial para obtenção do grau de Mestre pelo Programa de Pós-Graduação em Design do Departamento de Artes \& Design do Centro de Teologia e Ciências Humanas da PUC-Rio. Aprovado pela Comissão Examinadora abaixo assinada.

Profa. Dra. Vera Damazio

Orientador

Departamento de Artes e Design - PUC-Rio

Profa. Dra. Carla Dias

Co-Orientador

Departamento de Artes e Design - PUC-Rio

Profa. Dra. Luiza Novaes

Membro - PUC-Rio

Profa. Dra. Teresa Bastos

Membro - UFRJ

Prof. Dr. Paulo Fernando Carneiro de Andrade Coordenador Setorial do Centro de Teologia e Ciências Humanas - PUC-Rio de de 
Todos os direitos reservados. É proibida a reprodução total ou parcial do trabalho sem autorização da universidade, do autor e do orientador.

\section{Roberto Betim Paes Leme}

Graduou-se em Comunicação Social pela Faculdade da Cidade - RJ em 1997. Trabalhou desde então como profissional atuante e fotógrafo participando de exposições nacionais e internacionais.

Ficha Catalográfica

Leme, Roberto Betim Paes

Consumo e transformação da imagem do surfe / Roberto Betim Paes Leme ; orientadora: Vera Damazio ; co-orientadora: Carla Dias. - 2009. 120 f. : il. (col.) ; $30 \mathrm{~cm}$

Dissertação (Mestrado em Artes e Design)Pontifícia Universidade Católica do Rio de Janeiro, Rio de Janeiro, 2009.

Inclui bibliografia

1. Artes - Teses. 2. Surfe. 3. Cultura. 4. Consumo. 5. Discurso editorial. 6. Publicidade. I. Damazio, Vera. II. Dias, Carla. III. Pontifícia Universidade Católica do Rio de Janeiro. Departamento de Artes e Design. IV. Título. 


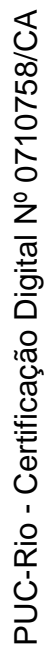

À minha família, pelo amor e carinho. 


\section{Agradecimentos}

Aos meus orientadores Vera Damazio e Carla Dias pelo incentivo, compreensão e sabedoria na condução dos trabalhos.

Aos colegas professores do Departamento de Artes e Design pelo auxílio e conselhos.

À CAPES e PUC-Rio pelos auxílios concedidos fundamentais para concretização deste trabalho.

Aos parceiros do Laboratório Design Memória e Emoção (LABMEMO) que trabalham e pensam em soluções para um mundo melhor.

Aos funcionários que pacientemente desembaraçaram as dificuldades apresentadas.

À comissão examinadora por toda seriedade necessária.

Aos meu amigos pela alegria e apoio.

Aos meu irmãos, especialmente Fernando e Tereza, pelo incentivo, ajuda e carinho ao longo desta jornada.

Aos meus pais que jamais me desampararam e nunca pouparam tempo, recursos e amor para que me tornasse uma pessoa melhor. 


\section{Resumo}

Leme, Roberto Betim Paes; Damazio, Vera. Consumo e transformação da imagem do surfe. Rio de Janeiro, 2009. 120p. Dissertação de Mestrado - Departamento de Artes \& Design, Pontifícia Universidade Católica do Rio de Janeiro.

O estudo propõe uma possível relação entre o discurso editorial e o publicitário na formação de uma imagem sobre a prática do surfe presente em nosso cotidiano. Mais especificamente, o trabalho apresenta uma reflexão sobre a construção dessa prática a partir de quem vive e consome os produtos vinculados a ela. Sendo assim, um método de pesquisa com viés antropológico foi desenvolvido. Após observar o surfe na publicidade, analisamos as publicações especializadas no sentido de compreender o que e para quem dizem os editores de tais veículos. Acreditamos que ao observar costumes e hábitos sob o prisma do consumo, podemos encontrar pistas importantes para entender o indivíduo e o design para o qual tais publicações se dirigem. Entendemos, por fim, que a prática do surfe à qual se faz referência ao longo do texto, carrega consigo elementos importantes na caracterização desse indivíduo.

\section{Palavras-chave}

Surfe; cultura; consumo; discurso editorial; publicidade 


\section{Abstract}

Leme, Roberto Betim Paes; Damazio, Vera (Advisor). Consumpition and transformation of surfing image. Rio de Janeiro, 2008. 120 p. MSc. Dissertation - Departamento de Artes \& Design, Pontifícia Universidade Católica do Rio de Janeiro.

The study proposes a possible relationship between the publishing and the advertising discourses in the idealization an image of the practice of surfing present in everyday life. More specifically, the work presents a reflection on the construction of this practice from those who live and consume products tied to it. Therefore, a research method with anthropological aproach was developed. After observing the surfing in advertising, specialized publications were analyzed, in order to understand what and who the editors were aiming with each media. We observed that consumers life style and habits can give important clues to understand the design adapted in the studied graphic material. We believe that the practice of surfing, wich is referred throghout the text, carries important elements in characterization of this individual.

\section{Keywords}

Surfing; culture; consumpition; publishing discourse; advertising. 


\section{SUMÁRIO}

1. Introdução 9

2. Do costume de ir à praia à prática do surfe 17

$\begin{array}{ll}\text { 2.1. "Cultura de praia" } & 18\end{array}$

2.2. A prática do surfe e seu passado 33

3. 0 consumo na prática do surfe 45

3.1. O surfe e seus bens de consumo 46

4. A representação do surfe no universo editorial 64

4.1. Publicações especializadas: as primeiras revistas de surfe 65

4.2. Nas redações das revistas: "estranhando" o familiar 75

4.2.1. Em campo: revistas Blackwater e Surfar 77

4.3. O discurso editorial da revista Alma Surf 89 4.3.1. Consciência, respeito à natureza, despojamento e culto às 92
raízes

5. Considerações finais 102

6. Referências bibliográficas 116 